\section{Informing the public}
A
s described by Laura Eggertson and Barbara Sibbald, ${ }^{1}$ several Canadian health care institutions are struggling to contain an outbreak of Clostridium difficile infection. Because this disease is not reportable, it is up to individual institutions to determine how (and even whether) to disseminate information about the problem; how- ever, this ad hoc approach is woefully inadequate.
The public ought to have been made aware of the rise in rates of $C$. difficile infection when the increase first mani- fested itself. This would have allowed people to make informed decisions re- garding, say, elective hospital proce- dures that require use of antibiotics or proton pump inhibitors and to seek and receive prompt diagnosis and treatment if they experienced diarrhea. In making this information available, hospitals would have been abiding by the princi- ples of transparency and accountability on an issue that concerns the public, thus instilling trust in our health care institutions. Once the issue had been brought to light, institutions could have solicited government response and as- sistance on an issue that is essentially

social and, therefore, political.

Instead, public health officers are struggling with the problem and hospital staff are attempting to reduce the incidence of infection, but without a nationwide consensus on appropriate strategies.

There is a false belief that the public, if informed about the increased risk of contracting the infection, would become panic-stricken. Yet several studies have shown that the public demands comprehensive information about both the risks and the benefits of medical care, ${ }^{2,3}$ so that they can exercise their right to make informed decisions. ${ }^{4}$

Perhaps health care providers lack the time or resources to properly inform patients about the many risks of care in the hospital setting. But this raises the question of what sort of a health care system we really want one where an ethic of informed consent overrides expediency and lack of resources or the other way around?

\section{Joseph Erban}

Member, Clinical Ethics Committee

Jewish General Hospital

Montréal, Que.

\section{References}

1. Eggertson L, Sibbald B. Hospitals battling outbreaks of C. difficile. CMA7 2004;171(1):19-21.
2. Geller G, Strauss M, Bernhardt BA, Holtzman NA. "Decoding" informed consent. Insights from women regarding breast cancer susceptibity testing. Hastings Cent Rep 1997;27:28-33.

3. Gert HJ. Avoiding surprises. A model for informing patients. Hasting Cent Rep 2002;32(5): 23-32.

4. Munch S. Moral wounds: complicated complications. FAMA 2001;285:1131-2.

DOI:10.1503/cmaj.1041050

\section{Letter from the Himalayas}

T t was with great enthusiasm tem1 pered by sadness that I read Geoff Ibbotson's description of his experiences in $\mathrm{Nepal}^{1}$ as I prepared to head home to Nepal this year. The beginning of February is a good time to take a peek at the Himalayas, as the skies become clearer and the white snow melts on the mountains. But the colour characterizing the mountains this year was red. The whole country has been caught up in a cycle of violence since the beginning of the Maoist insurgency, which has claimed over 10000 lives and has now reached the capital city of Kathmandu.

We are all aware of the deplorable level of health care available in Nepal, but few, including me (a Nepalese native), are aware that the system can also offer good care at an affordable cost. 